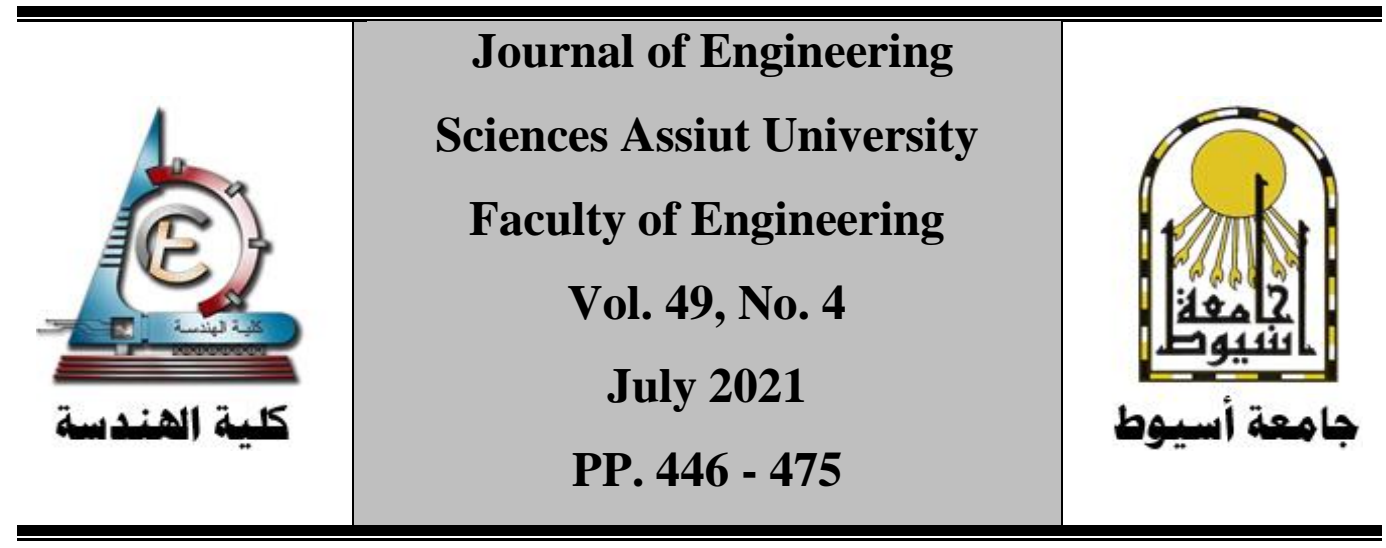

\title{
Evaluation of the Hot Asphalt Mix Aggregate Gradation Using Bailey Method: State-of-the-art
}

\author{
Kareem Othman ${ }^{1,2}$ \\ ${ }^{1}$ Civil engineering department, University of Toronto, Toronto, Canada, 35 \\ St George St, Toronto, ON M5S 1A4 \\ kareem.othman@mail.utoronto.ca \\ ${ }^{2}$ Public works department, Faculty of engineering, Cairo University, Giza, \\ Egypt karemmohamed1993@cu.edu.eg
}

Received 5 April 2021; Revised 17 May 2021; Accepted 23 May 2021

\begin{abstract}
The selection of the aggregate gradation, in the process of the asphalt mix design, is one of the most critical steps because it accounts for the overall strength of the asphalt mixture in terms of resisting the permanent deformation or rutting. This paper focuses on evaluating the current aggregate gradation selection procedure for the hot asphalt mix (HAM) using the three Bailey ratios. Additionally, this study analyzes, theoretically, the compaction and performance characteristics of the resulting HAM designed using the traditional design procedures which follow the trial-and-error technique in order to have a mix that satisfies the specification range. Results show that $14 \%$ of the samples prepared using the traditional technique satisfy the Bailey method guidelines and thus indicate good performance in the field. However, almost $80 \%$ of the asphalt mixes are tender asphalt mixes that are prone to segregation in the field, and 6 to $7 \%$ of the asphalt mixes are hard to compact.
\end{abstract}


Based on the findings of this research, it is recommended that the Bailey Method analysis process should be incorporated into the mix design process as an additional tool to develop and select trial blends for the design of the asphalt mixes in Egypt.

Keywords: Aggregate gradation, Asphalt mix, Asphalt pavement, Bailey design method.

\section{Introduction}

The transportation system is an essential element for any long-term progress of a country. In general, one of the most important indices for the socio-economic development of nations is the growth of the road network. In 2014, Egypt started a major plan for the development of the transportation infrastructure [[1]]. This plan managed to significantly improve the quality of roads in Egypt. As a result of this program, in 2020, Egypt ranked the second in Africa and 28th globally in terms of the quality of roads [[2]], jumping from the 118th place globally a year before [[3]]. Thus, the appropriate planning, designing, and construction of road networks with the proper materials and soil properties is an essential step for the construction of these roads. Flexible pavement is the most commonly type of pavement used in Egypt [[4]-[5]]. In general, flexible pavement consists of a surface pavement layer in direct contact with the running traffic followed by aggregate layers on top of the soil. The asphalt pavement surface layer consists of hot mix asphalt and the thickness of this layer is estimated based on multiple factors such as the traffic loading, life cycle, the properties of the asphalt mix components, environmental conditions, and properties of the subgrade soil properties [[6]]. The asphalt mix consists of aggregate, which represents hard pieces of rock, binder, and air voids. The performance of the hot asphalt mix depends on the characteristics of its constituents and the proportion of each. Approximately $95 \%$ of the asphalt mix weight consists of aggregate [[7]]. Thus, the characteristics of the mix mainly depend on the aggregate properties and its gradation. Thus, the main source of compressive strength and resistance to movement under traffic loads or heavy loads comes from the aggregate and its properties such as shape, hardness, texture, and gradation of the aggregate. Of these properties, gradation is the most unstructured [[8]]. However, it is mentioned in the 
literature that aggregate gradation is one of the most important factors that influence the asphalt mix performance as mentioned in the study by Ahlrich [[9]]. Button et al. [[10]] show that aggregate gradation is one of the main factors that influence the rutting performance of the asphalt pavement. Additionally, Stakston and Bahia [[11]] state that "the rutting performance is highly dependent on aggregate gradation" that even the mixes with the best possible materials would fail and provide poor asphalt mixes without a proper gradation. Bissada [[12]] reported that the aggregate gradation significantly influences the compaction of bituminous mixes. El-Basyouny and Mamlouk [[13]] show that the aggregate gradation and the nominal maximum aggregate size significantly affect the rutting performance of the asphalt pavement and stated that the coarser gradations are expected to have better performance than finer gradations.

Over the last few years, rutting has been recognized as one of the major pavement distresses noticed in Egyptian roads [[14]] and this became a concerning issue for highway engineers because of the developments in truck loads and the associated increase in the wheel load and tire pressures on the pavement, which increase the severity of this issue [[15]]. Rutting can be defined as the permanent deformation that appears on the pavement surface on the wheel path referring to accumulation in the irrecoverable strains from repeated load cycles. Rutting can be hazardous as it might cause sliding of vehicles and drivers might lose control of their vehicles. In general, there are two types of rutting: subgrade rutting and asphalt mix rutting. Subgrade rutting is caused as a result of a structural design problem, such as the selection of a thin pavement thickness, rather than a material problem. On the other hand, the asphalt mix rutting is caused as a result of problems in the mix design or problems in the compaction. Rutting in the asphalt mix can be defined as the deformations that cannot be recovered within the asphalt layer when the subgrade does not rut yet. This study focuses on the rutting of the hot asphalt mix and this type of rutting is, generally, related to the mixes that are exposed to high temperatures and subjected to heavy traffic. In the literature, it is extensively cited that aggregate gradation is the main factor that influences the rutting performance of the asphalt mix [[12]-[14]]. In general, asphalt mixes are designed following the trialand-error approach to select the aggregate gradation that satisfies some aggregate gradation specifications or limits. Recently, the Bailey method for gradation selection was developed to provide some guidelines on the 
selection of the appropriate aggerate gradation that improves the performance of the asphalt mix in the field. Thus, the main objectives of this study are:

- Evaluating the current aggregate gradation selection procedure for the hot asphalt mix using the three Bailey ratios.

- Analyze, theoretically, the compaction and performance characteristics of the resulting hot mix asphalt mixture(s).

- Understanding the impact of the NMAS on the performance of the asphalt mix. In other words, the impact of the NMAS on the three Bailey ratios.

- $\quad$ Illustrating the importance of incorporating an analytical gradation design and evaluation method into the Marshal mix design procedure.

\subsection{The Bailey Design method:}

The Bailey method is a systematic approach for choosing the aggregate gradation that provides interlocking between the aggregate particles. Additionally, this method provides a set of tools for the evaluation of the final performance of the mix. These tools provide better understanding of the influence of the aggregate gradation on the asphalt mix. Thus, this method provides the designers with some tools to develop and adjust the aggregate blend to ensure good aggregate packing, offer the desired resistance to permanent deformation, and at the same time satisfy the volumetric properties that provide resistance to environmental distress [[8]]. The Bailey method was proposed in the 1980s by Robert D. Bailey and it focuses on choosing the aggregate structure that improves the air voids, voids in mineral aggregate (VMA) and overall workability of the mix when using Marshall or Superpave method [[15]]. The main scope of this approach is the aggregate packing that includes coarse aggregate structure and the particles fit into the voids within that structure. Over the last few years, this approach was used in multiple countries such as the United Arab Emirates, France, Canada and many states in the United States and results showed that this method improves the performance of the asphalt mixes [[16], [17]]. However, the Bailey method has never been used in Egypt. In this paper, the Bailey method will be used to evaluate the traditional asphalt mix design process and analyze the performance of the resulting asphalt mixes. 


\subsection{Benefits of the Bailey Method:}

Over the last few years, the Bailey Method for the selection of the aggrege gradation was tested and compared with the traditional methods to quantify the impact of following this new approach. Zaniewski and Mason show that the Bailey Method can be a very useful tool to design an optimal mix that provides the best asphalt mix performance and with the required volumetric properties [[18]]. Thompson showed that the Bailey method of gradation can be used for the prediction of the rutting performance of the asphalt mix as the increasing VMA (which increased by decreasing the coarse aggregate (CA)) tended to increase rutting [[19]]. In 2012, Zhu Wei et al, showed that the asphalt mixes designed using the Bailey method have much better performance than the mixes designed by the traditional method in terms of crack resistance at low temperature, durability and rutting resistance at high temperature [[20]]. In 2013, Shang et al. showed similar results and concluded that the use of the Bailey method, in the mix design of a Japanese airfield pavement, procedures gives better results and produces better rutting resistance mixtures [[21]]. Similarly, in 2014, Manjunath and Poornachandra showed that the asphalt mixes designed following the Bailey gradation method perform better than the asphalt mixes designed using the traditional technique [[22]]. In 2015, Teklu showed that the mixes designed using the Bailey method give better rutting performance than the Asphalt Institute gradation method. Additionally, there is a high correlation between the CA (coarse aggregate) ratio calculated using the Bailey method and the rutting resistance; thus, this correlation can be used for the prediction of the asphalt mix rutting performance [[23]]. In 2016, Oufa and Abdolsamed showed that the Bailey method is useful for evaluating the aggregate blends and that mixes with coarse gradations are better in resisting rutting [[24]]. In 2019, Komba et al. studied the relation between the aggregate gradation and the compatibility of HAM, and results suggest that the Bailey ratios may be very useful to predict HAM compatibility [[25]]. In 2020, Ghuzlan et al, demonstrated that using the Bailey aggregate gradation approach gives good aggregate packing expressed by good rutting performance [15].

\subsection{Main principles of the Bailey Method:}

As discussed in Jones (2006) [[26]], there are four main principles of the Bailey Method: 
- Principle 1: this principle provides a new definition for the coarse particles and the fine particles. This method employs the Nominal Maximum Aggregate Size (NMAS) to estimate the volume of void in the coarse particles. Thus, this method defined a new sieve called the primary control sieve (PCS) for categorizing the particles into coarse and fine particles. In general, the gradation is considered as coarse if the percentage of the particles retained on the PCS is higher than $50 \%$. On the other hand, the gradation is considered fine gradation if the percentage of the passing from the PCS is higher than $50 \%$.

- Principle 2: this principle is concerned with the coarse particles determined by the PCS. More specifically, this principle focuses on the packing of the coarse particles. In other words, the distribution of the coarse particles. This principle introduces a new sieve called the half-size and divides the coarse particles into two categories one coarse and the other is the fine part that fills the void between the coarse part in the coarse particles.

- Principle 3: focuses on the coarse particles of the fine part and the packing of this category.

- Principle 4: focuses on the fine part of fine aggregate and the packing of the fine portion of the gradation in the blend.

The four principles are shown in Figure 1.

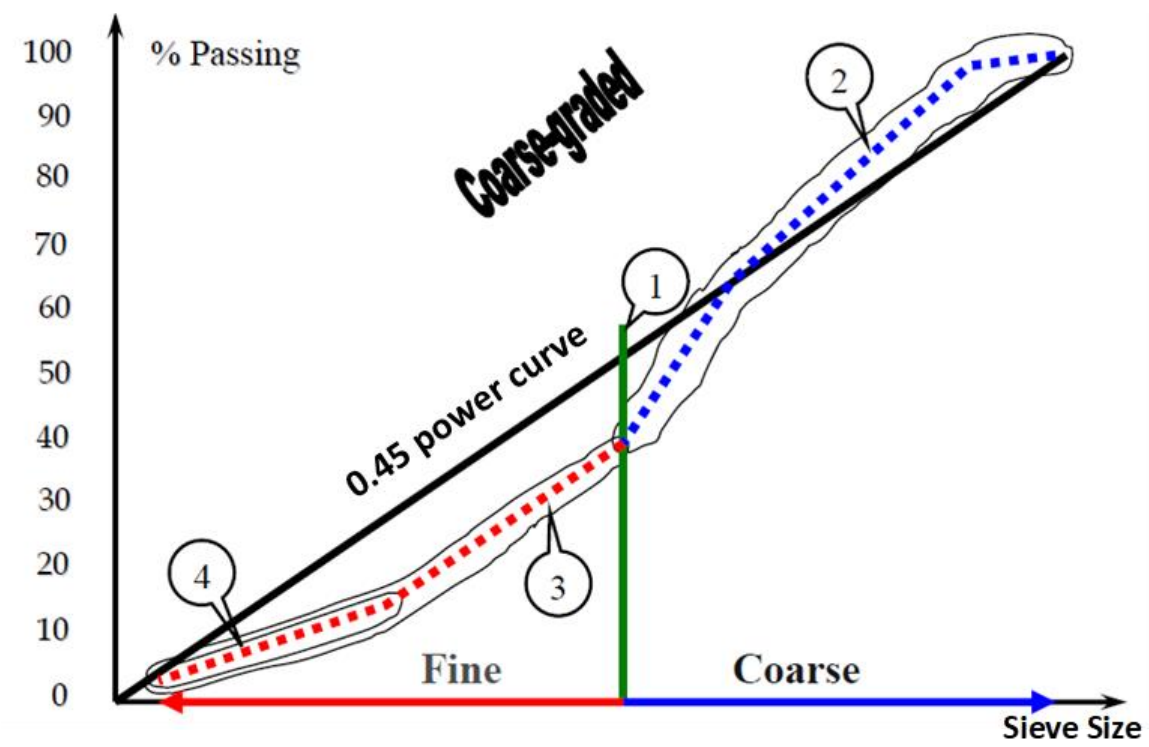

Figure 1. the four principles of the Bailey Method [[27]] 


\section{Methodology}

As discussed above, the Bailey method has been used and tested in multiple countries and the results show that the three Bailey ratios have direct correlations with the asphalt mix performance characteristics. However, this method has never been used in Egypt before. Thus, in this study, the Bailey method will be used to evaluate the aggregate structure for multiple asphalt mixes designed using the standard procedures in Egypt. In this study, 103 asphalt mix samples, that were used in the construction of roads in Egypt between 2015 and 2019, will be evaluated using the three Bailey ratios to evaluate their performance and provide some indication about their resistance and performance in the field. Thus, this study will focus on the two common aggregate gradations used for the construction of roads in Egypt (4C and 3D) [[4]-[5]]. Additionally, the aggregate type used in the samples tested is dolomite, which is the main aggregate type used in the asphalt mixes in Egypt [[4]]. Figure 2 shows the locations where these gradations were used for the construction of the wearing course layer. Of the 103 samples tested in this study, 64 follow the 3D aggregate gradation and 39 follow the 4C aggregate gradation. Figures 3 and 4 show the aggregate gradation for the asphalt mix samples with the specification limits shown in the figure in black. Finally, Tables 1 and 2 summarize the main characteristics of the aggregate gradation used, such as the control sieves and the three Bailey ratios, for every asphalt mix. 


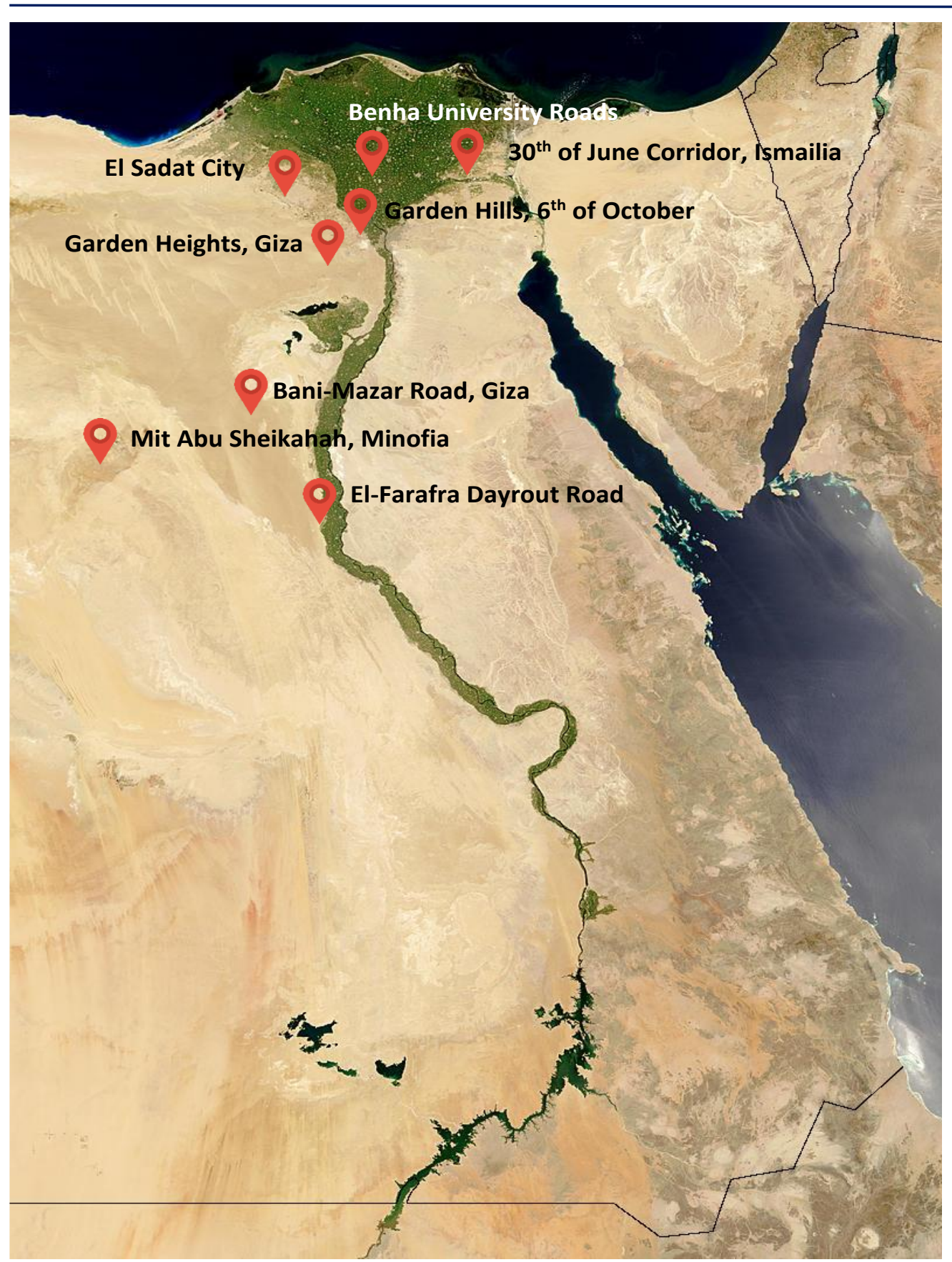

Figure 2. the locations where the aggregate gradations were used for the construction of the wearing course layer in the HAM 


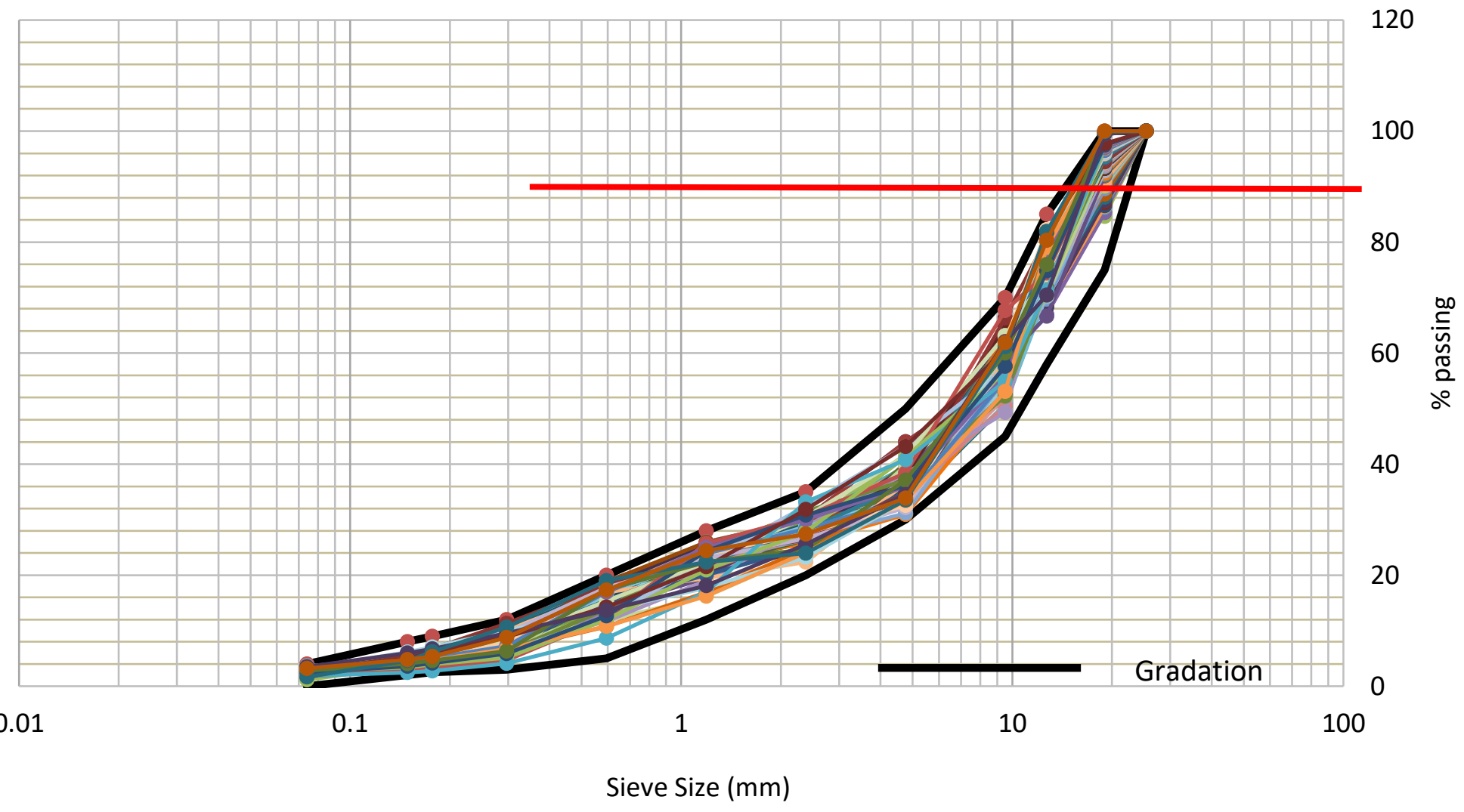

Figure 3. Aggregate gradation for all 3D samples with the gradation limits 


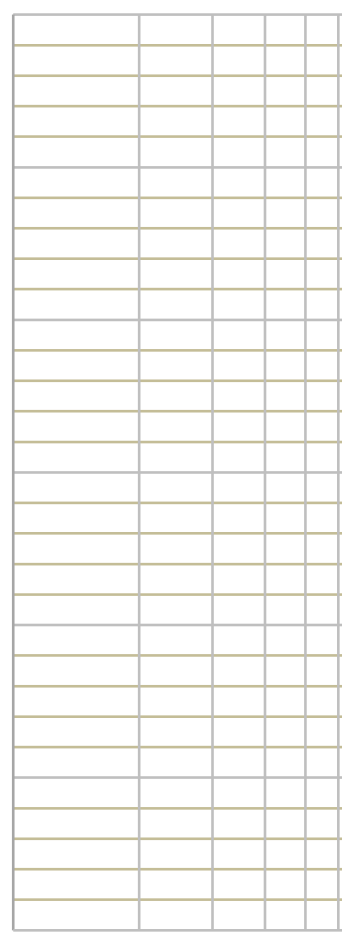

0.01

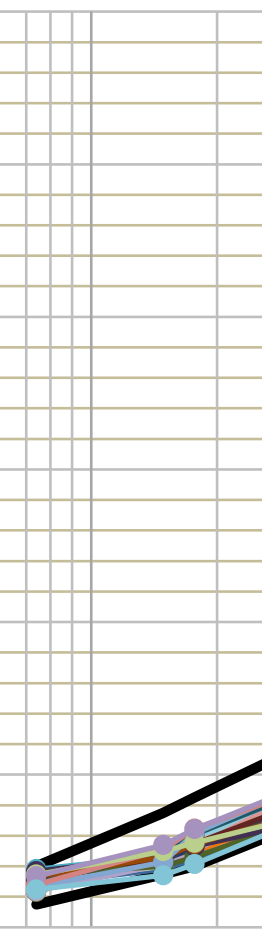

0.1

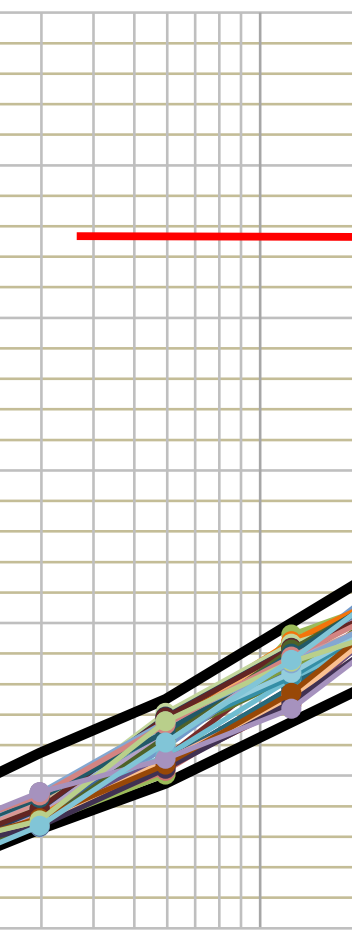

1

Sieve Size $(\mathrm{mm})$

Figure 4. Aggregate gradation for all 4D samples with the gradation limits 
Table 1: Control sieves and the three Bailey rations for the 3D samples

\begin{tabular}{|c|c|c|c|c|c|c|c|c|c|c|c|c|c|}
\hline OAC & NMAS(mm) & $\operatorname{PCS}(\mathrm{mm})$ & $\mathrm{SCS}(\mathrm{mm})$ & $\mathrm{TSC}(\mathrm{mm})$ & $\mathrm{HS}(\mathrm{mm})$ & \%P(NMPS) & $\% \mathrm{P}(\mathrm{PCS})$ & $\% \mathrm{P}(\mathrm{SCS})$ & $\% \mathrm{P}(\mathrm{TSC})$ & $\% \mathrm{P}(\mathrm{HS})$ & CA & FAc & FAf \\
\hline 4.75 & 25 & 4.75 & 1.18 & 0.3 & 12.5 & 87 & 40.5 & 21 & 8 & 64 & 0.65 & 0.52 & 0.38 \\
\hline 4.75 & 25 & 4.75 & 1.18 & 0.3 & 12.5 & 90 & 36 & 20 & 8 & 65 & 0.83 & 0.56 & 0.4 \\
\hline 4.7 & 25 & 4.75 & 1.18 & 0.3 & 12.5 & 88 & 38 & 22 & 5.2 & 63 & 0.68 & 0.58 & 0.24 \\
\hline 4.7 & 25 & 4.75 & 1.18 & 0.3 & 12.5 & 90 & 38 & 21 & 7 & 60 & 0.55 & 0.55 & 0.33 \\
\hline 5.23 & 25 & 4.75 & 1.18 & 0.3 & 12.5 & 88 & 34 & 24 & 6 & 66 & 0.94 & 0.71 & 0.25 \\
\hline 4.75 & 25 & 4.75 & 1.18 & 0.3 & 12.5 & 90 & 38 & 21 & 5 & 64 & 0.72 & 0.55 & 0.24 \\
\hline 4.85 & 25 & 4.75 & 1.18 & 0.3 & 12.5 & 90 & 38 & 20 & 4 & 64 & 0.72 & 0.53 & 0.2 \\
\hline 4.8 & 25 & 4.75 & 1.18 & 0.3 & 12.5 & 91 & 37 & 18 & 6 & 66 & 0.85 & 0.49 & 0.33 \\
\hline 4.7 & 25 & 4.75 & 1.18 & 0.3 & 12.5 & 92 & 36 & 23 & 5 & 53 & 0.36 & 0.64 & 0.22 \\
\hline 4.75 & 25 & 4.75 & 1.18 & 0.3 & 12.5 & 90 & 36 & 20 & 6.5 & 58 & 0.52 & 0.56 & 0.33 \\
\hline 4.75 & 25 & 4.75 & 1.18 & 0.3 & 12.5 & 90 & 32 & 24 & 6 & 64 & 0.89 & 0.75 & 0.25 \\
\hline 4.85 & 25 & 4.75 & 1.18 & 0.3 & 12.5 & 90 & 34 & 18 & 6 & 53 & 0.4 & 0.53 & 0.33 \\
\hline 4.8 & 19 & 2.36 & 0.6 & 0.15 & 9.5 & 90 & 33 & 21 & 6 & 53 & 0.43 & 0.64 & 0.29 \\
\hline 4.75 & 19 & 2.36 & 0.6 & 0.15 & 9.5 & 88 & 36 & 19 & 4 & 58 & 0.52 & 0.53 & 0.21 \\
\hline 4.8 & 19 & 2.36 & 0.6 & 0.15 & 9.5 & 88 & 34 & 23 & 7 & 50 & 0.32 & 0.68 & 0.3 \\
\hline 4.65 & 19 & 2.36 & 0.6 & 0.15 & 9.5 & 90 & 32.13 & 21.45 & 5.45 & 53.48 & 0.46 & 0.67 & 0.25 \\
\hline 4.75 & 19 & 2.36 & 0.6 & 0.15 & 9.5 & 90 & 39.85 & 18.35 & 4.92 & 55.36 & 0.35 & 0.46 & 0.27 \\
\hline 4.75 & 19 & 2.36 & 0.6 & 0.15 & 9.5 & 90 & 39.85 & 18.35 & 4.92 & 55.36 & 0.35 & 0.46 & 0.27 \\
\hline 4.8 & 19 & 2.36 & 0.6 & 0.15 & 9.5 & 90 & 34.07 & 17.82 & 5.41 & 55.1 & 0.47 & 0.52 & 0.3 \\
\hline 4.75 & 19 & 2.36 & 0.6 & 0.15 & 9.5 & 90 & 34.97 & 16.82 & 6.74 & 57.66 & 0.54 & 0.48 & 0.4 \\
\hline 4.7 & 19 & 2.36 & 0.6 & 0.15 & 9.5 & 90 & 32.71 & 19.48 & 6.15 & 54.64 & 0.48 & 0.6 & 0.32 \\
\hline 4.7 & 19 & 2.36 & 0.6 & 0.15 & 9.5 & 90 & 29.2 & 20.76 & 5.58 & 50.66 & 0.43 & 0.71 & 0.27 \\
\hline
\end{tabular}


Othman K., Evaluation of the Hot Asphalt Mix Aggregate Gradation Using Bailey Method

\begin{tabular}{|c|c|c|c|c|c|c|c|c|c|c|c|c|c|}
\hline OAC & $\operatorname{NMAS}(\mathrm{mm})$ & $\mathrm{PCS}(\mathrm{mm})$ & $\mathrm{sCS}(\mathrm{mm})$ & $\mathrm{TSC}(\mathrm{mm})$ & $\mathrm{HS}(\mathrm{mm})$ & $\% \mathrm{P}(\mathrm{NMPS})$ & $\% \mathrm{P}(\mathrm{PCS})$ & $\% \mathrm{P}(\mathrm{SCS})$ & $\% \mathrm{P}(\mathrm{TSC})$ & $\% \mathrm{P}(\mathrm{HS})$ & CA & FAc & FAf \\
\hline 4.8 & 19 & 2.36 & 0.6 & 0.15 & 9.5 & 90 & 31.79 & 19.98 & 5.13 & 53.56 & 0.47 & 0.63 & 0.26 \\
\hline 4.8 & 19 & 2.36 & 0.6 & 0.15 & 9.5 & 90 & 31.53 & 19.45 & 6.38 & 49.72 & 0.36 & 0.62 & 0.33 \\
\hline 4.7 & 19 & 2.36 & 0.6 & 0.15 & 9.5 & 90 & 34.59 & 13.88 & 6.29 & 55.63 & 0.47 & 0.4 & 0.45 \\
\hline 4.75 & 19 & 2.36 & 0.6 & 0.15 & 9.5 & 90 & 34.19 & 16.59 & 4 & 54.51 & 0.45 & 0.49 & 0.24 \\
\hline 4.75 & 19 & 2.36 & 0.6 & 0.15 & 9.5 & 90 & 33.85 & 19.15 & 7.11 & 51.63 & 0.37 & 0.57 & 0.37 \\
\hline 4.95 & 19 & 2.36 & 0.6 & 0.15 & 9.5 & 90 & 33.03 & 20.07 & 4.86 & 58.94 & 0.63 & 0.61 & 0.24 \\
\hline 4.85 & 19 & 2.36 & 0.6 & 0.15 & 9.5 & 90 & 33.71 & 20.09 & 4.93 & 55.93 & 0.5 & 0.6 & 0.25 \\
\hline 4.7 & 19 & 2.36 & 0.6 & 0.15 & 9.5 & 90 & 34.41 & 20.03 & 5.59 & 62.02 & 0.73 & 0.58 & 0.28 \\
\hline 4.85 & 19 & 2.36 & 0.6 & 0.15 & 9.5 & 90 & 31.72 & 19.23 & 6.46 & 49.77 & 0.36 & 0.61 & 0.34 \\
\hline 4.85 & 19 & 2.36 & 0.6 & 0.15 & 9.5 & 90 & 33.18 & 21.56 & 5.1 & 56.47 & 0.54 & 0.65 & 0.24 \\
\hline 4.65 & 19 & 2.36 & 0.6 & 0.15 & 9.5 & 90 & 32.2 & 20.37 & 7.38 & 55.64 & 0.53 & 0.63 & 0.36 \\
\hline 4.75 & 19 & 2.36 & 0.6 & 0.15 & 9.5 & 90 & 31.95 & 22.07 & 5.07 & 52.76 & 0.44 & 0.69 & 0.23 \\
\hline 4.75 & 19 & 2.36 & 0.6 & 0.15 & 9.5 & 90 & 29.51 & 19.69 & 4.97 & 52.41 & 0.48 & 0.67 & 0.25 \\
\hline 4.65 & 19 & 2.36 & 0.6 & 0.15 & 9.5 & 90 & 31.5 & 19.53 & 5.13 & 47.98 & 0.32 & 0.62 & 0.26 \\
\hline 4.92 & 19 & 2.36 & 0.6 & 0.15 & 9.5 & 90 & 30.74 & 20.67 & 4.12 & 55.81 & 0.57 & 0.67 & 0.2 \\
\hline 4.8 & 19 & 2.36 & 0.6 & 0.15 & 9.5 & 90 & 34.65 & 14.78 & 4.96 & 47.52 & 0.25 & 0.43 & 0.34 \\
\hline 4.75 & 19 & 2.36 & 0.6 & 0.15 & 9.5 & 90 & 32.09 & 19.58 & 5.13 & 52.74 & 0.44 & 0.61 & 0.26 \\
\hline 4.75 & 19 & 2.36 & 0.6 & 0.15 & 9.5 & 90 & 31.11 & 18 & 4.42 & 55.31 & 0.54 & 0.58 & 0.25 \\
\hline 4.7 & 19 & 2.36 & 0.6 & 0.15 & 9.5 & 90 & 31.45 & 17.29 & 5.35 & 54 & 0.49 & 0.55 & 0.31 \\
\hline 4.83 & 19 & 2.36 & 0.6 & 0.15 & 9.5 & 90 & 31.11 & 20.21 & 6.84 & 59.45 & 0.7 & 0.65 & 0.34 \\
\hline 4.8 & 19 & 2.36 & 0.6 & 0.15 & 9.5 & 90 & 35.02 & 18.41 & 4.78 & 50.01 & 0.3 & 0.53 & 0.26 \\
\hline 4.75 & 19 & 2.36 & 0.6 & 0.15 & 9.5 & 90 & 30.65 & 19.48 & 5.68 & 55.29 & 0.55 & 0.64 & 0.29 \\
\hline
\end{tabular}




\begin{tabular}{|c|c|c|c|c|c|c|c|c|c|c|c|c|c|}
\hline OAC & $\operatorname{NMAS}(\mathrm{mm})$ & $\mathrm{PCS}(\mathrm{mm})$ & $\mathrm{SCS}(\mathrm{mm})$ & $\mathrm{TSC}(\mathrm{mm})$ & $\mathrm{HS}(\mathrm{mm})$ & \%P(NMPS) & $\% \mathrm{P}(\mathrm{PCS})$ & $\% \mathrm{P}(\mathrm{SCS})$ & $\% \mathrm{P}(\mathrm{TSC})$ & $\% \mathrm{P}(\mathrm{HS})$ & CA & FAc & FAf \\
\hline 4.7 & 19 & 2.36 & 0.6 & 0.15 & 9.5 & 90 & 32.81 & 18.1 & 5.56 & 56.92 & 0.56 & 0.55 & 0.31 \\
\hline 5 & 19 & 2.36 & 0.6 & 0.15 & 9.5 & 90 & 29.61 & 13.05 & 4.63 & 56.16 & 0.61 & 0.44 & 0.35 \\
\hline 4.8 & 19 & 2.36 & 0.6 & 0.15 & 9.5 & 90 & 38.85 & 16.46 & 3.82 & 54.64 & 0.35 & 0.42 & 0.23 \\
\hline 4.65 & 19 & 2.36 & 0.6 & 0.15 & 9.5 & 90 & 37.06 & 18.16 & 4.55 & 59.14 & 0.54 & 0.49 & 0.25 \\
\hline 4.65 & 19 & 2.36 & 0.6 & 0.15 & 9.5 & 90 & 37.06 & 18.16 & 4.55 & 59.14 & 0.54 & 0.49 & 0.25 \\
\hline 4.85 & 19 & 2.36 & 0.6 & 0.15 & 9.5 & 90 & 29.87 & 19.84 & 5.62 & 52.36 & 0.47 & 0.66 & 0.28 \\
\hline 4.95 & 19 & 2.36 & 0.6 & 0.15 & 9.5 & 90 & 28.54 & 15.06 & 7.04 & 52.99 & 0.52 & 0.53 & 0.47 \\
\hline 4.77 & 19 & 2.36 & 0.6 & 0.15 & 9.5 & 90 & 30.07 & 19.2 & 4.76 & 53.11 & 0.49 & 0.64 & 0.25 \\
\hline 4.8 & 19 & 2.36 & 0.6 & 0.15 & 9.5 & 90 & 31.37 & 19.64 & 5.16 & 50.69 & 0.39 & 0.63 & 0.26 \\
\hline 4.97 & 19 & 2.36 & 0.6 & 0.15 & 9.5 & 90 & 35.1 & 17.46 & 3.38 & 61.69 & 0.69 & 0.5 & 0.19 \\
\hline 4.75 & 19 & 2.36 & 0.6 & 0.15 & 9.5 & 90 & 35.94 & 15.66 & 4.01 & 53.81 & 0.39 & 0.44 & 0.26 \\
\hline 4.75 & 19 & 2.36 & 0.6 & 0.15 & 9.5 & 90 & 33.25 & 19.85 & 6.01 & 51.07 & 0.36 & 0.6 & 0.3 \\
\hline 4.75 & 19 & 2.36 & 0.6 & 0.15 & 9.5 & 90 & 37.7 & 11.98 & 2.81 & 52.28 & 0.31 & 0.32 & 0.23 \\
\hline 4.85 & 19 & 2.36 & 0.6 & 0.15 & 9.5 & 90 & 28.95 & 12.63 & 4.65 & 47.82 & 0.36 & 0.44 & 0.37 \\
\hline 4.9 & 19 & 2.36 & 0.6 & 0.15 & 9.5 & 90 & 33.84 & 17.06 & 4.22 & 52.91 & 0.4 & 0.5 & 0.25 \\
\hline 5 & 19 & 2.36 & 0.6 & 0.15 & 9.5 & 90 & 37.21 & 16.44 & 6 & 55.01 & 0.4 & 0.44 & 0.37 \\
\hline 4.92 & 19 & 2.36 & 0.6 & 0.15 & 9.5 & 90 & 31.19 & 19.12 & 4.59 & 53.85 & 0.49 & 0.61 & 0.24 \\
\hline 4.75 & 19 & 2.36 & 0.6 & 0.15 & 9.5 & 90 & 30.61 & 15.35 & 6.79 & 56.03 & 0.58 & 0.5 & 0.44 \\
\hline 5.42 & 19 & 2.36 & 0.6 & 0.15 & 9.5 & 90 & 28.12 & 19.92 & 5.8 & 51.04 & 0.47 & 0.71 & 0.29 \\
\hline 5.08 & 19 & 2.36 & 0.6 & 0.15 & 9.5 & 90 & 30.39 & 19.35 & 5.08 & 52.39 & 0.46 & 0.64 & 0.26 \\
\hline
\end{tabular}


Othman K., Evaluation of the Hot Asphalt Mix Aggregate Gradation Using Bailey Method

Table 2: Control sieves and the three Bailey rations for the 4C samples

\begin{tabular}{|c|c|c|c|c|c|c|c|c|c|c|c|c|c|}
\hline OAC & $\mathrm{NMAS}(\mathrm{mm})$ & $\mathrm{PCS}(\mathrm{mm})$ & $\mathrm{SCS}(\mathrm{mm})$ & $\mathrm{TSC}(\mathrm{mm})$ & $\mathrm{HS}(\mathrm{mm})$ & \%P(NMPS) & $\% \mathrm{P}(\mathrm{PCS})$ & $\% \mathrm{P}(\mathrm{SCS})$ & $\% \mathrm{P}(\mathrm{TSC})$ & $\% \mathrm{P}(\mathrm{HS})$ & $\mathrm{CA}$ & FAC & FAf \\
\hline 5.25 & 25 & 4.75 & 1.18 & 0.3 & 12.5 & 90.07673 & 49.95 & 31.25 & 11.23 & 65.74 & 0.46 & 0.63 & 0.36 \\
\hline 5.28 & 25 & 4.75 & 1.18 & 0.3 & 12.5 & 90.03148 & 48.06 & 32.7 & 11.26 & 66.79 & 0.56 & 0.68 & 0.34 \\
\hline 5.35 & 19 & 2.36 & 0.6 & 0.15 & 9.5 & 90 & 49.04 & 32.35 & 11.44 & 74.05 & 0.96 & 0.66 & 0.35 \\
\hline 5.35 & 19 & 2.36 & 0.6 & 0.15 & 9.5 & 90 & 49.36 & 30.26 & 10.59 & 73.35 & 0.9 & 0.61 & 0.35 \\
\hline 5.25 & 19 & 2.36 & 0.6 & 0.15 & 9.5 & 90 & 49.86 & 30.27 & 10.56 & 70.56 & 0.7 & 0.61 & 0.35 \\
\hline 5.3 & 19 & 2.36 & 0.6 & 0.15 & 9.5 & 90 & 52.88 & 27.58 & 12.23 & 66.95 & 0.43 & 0.52 & 0.44 \\
\hline 5.25 & 19 & 2.36 & 0.6 & 0.15 & 9.5 & 90 & 53.57 & 28.48 & 12.65 & 67.28 & 0.42 & 0.53 & 0.44 \\
\hline 5.2 & 19 & 2.36 & 0.6 & 0.15 & 9.5 & 90 & 53.77 & 26.13 & 11.01 & 67.28 & 0.41 & 0.49 & 0.42 \\
\hline 5.2 & 19 & 2.36 & 0.6 & 0.15 & 9.5 & 90 & 53.77 & 26.13 & 11.01 & 67.28 & 0.41 & 0.49 & 0.42 \\
\hline 5.35 & 19 & 2.36 & 0.6 & 0.15 & 9.5 & 90 & 48.33 & 31.29 & 10.49 & 71.45 & 0.81 & 0.65 & 0.34 \\
\hline 5.45 & 19 & 2.36 & 0.6 & 0.15 & 9.5 & 90 & 55.62 & 29.04 & 10.38 & 68.97 & 0.43 & 0.52 & 0.36 \\
\hline 5.55 & 19 & 2.36 & 0.6 & 0.15 & 9.5 & 90 & 51.1 & 24.54 & 11.24 & 63.27 & 0.33 & 0.48 & 0.46 \\
\hline 5.25 & 19 & 2.36 & 0.6 & 0.15 & 9.5 & 90 & 49.38 & 28.42 & 11.19 & 64.43 & 0.42 & 0.58 & 0.39 \\
\hline 5.25 & 19 & 2.36 & 0.6 & 0.15 & 9.5 & 90 & 47.95 & 28.27 & 12.11 & 64.25 & 0.46 & 0.59 & 0.43 \\
\hline 5.25 & 19 & 2.36 & 0.6 & 0.15 & 9.5 & 90 & 48.53 & 26.62 & 12.02 & 67.89 & 0.6 & 0.55 & 0.45 \\
\hline 5.35 & 19 & 2.36 & 0.6 & 0.15 & 9.5 & 90 & 52.31 & 30.44 & 9.28 & 66.95 & 0.44 & 0.58 & 0.3 \\
\hline 4.9 & 19 & 2.36 & 0.6 & 0.15 & 9.5 & 90 & 54.98 & 28.66 & 8.81 & 69.32 & 0.47 & 0.52 & 0.31 \\
\hline 5.45 & 19 & 2.36 & 0.6 & 0.15 & 9.5 & 90 & 52.75 & 24.05 & 10.34 & 68.32 & 0.49 & 0.46 & 0.43 \\
\hline 5.2 & 19 & 2.36 & 0.6 & 0.15 & 9.5 & 90 & 46.72 & 29.01 & 10.13 & 67.59 & 0.64 & 0.62 & 0.35 \\
\hline 5.35 & 19 & 2.36 & 0.6 & 0.15 & 9.5 & 90 & 51.75 & 25.08 & 11.03 & 67.03 & 0.46 & 0.48 & 0.44 \\
\hline 5.25 & 19 & 2.36 & 0.6 & 0.15 & 9.5 & 90 & 52.08 & 28.27 & 10.64 & 71.8 & 0.7 & 0.54 & 0.38 \\
\hline 5.25 & 19 & 2.36 & 0.6 & 0.15 & 9.5 & 90 & 48.43 & 31.16 & 10 & 63.42 & 0.41 & 0.64 & 0.32 \\
\hline
\end{tabular}




\begin{tabular}{|c|c|c|c|c|c|c|c|c|c|c|c|c|c|}
\hline OAC & NMAS(mm) & $\mathrm{PCS}(\mathrm{mm})$ & $\mathrm{SCS}(\mathrm{mm})$ & $\mathrm{TSC}(\mathrm{mm})$ & $\mathrm{HS}(\mathrm{mm})$ & $\% \mathrm{P}(\mathrm{NMPS})$ & $\% \mathrm{P}(\mathrm{PCS})$ & $\% \mathrm{P}(\mathrm{SCS})$ & $\% \mathrm{P}(\mathrm{TSC})$ & $\% \mathrm{P}(\mathrm{HS})$ & CA & FAc & FAf \\
\hline 5.25 & 19 & 2.36 & 0.6 & 0.15 & 9.5 & 90 & 49.96 & 29.32 & 12.04 & 66.73 & 0.5 & 0.59 & 0.41 \\
\hline 5.5 & 19 & 2.36 & 0.6 & 0.15 & 9.5 & 90 & 48.11 & 29.77 & 11 & 68.28 & 0.64 & 0.62 & 0.37 \\
\hline 5.4 & 19 & 2.36 & 0.6 & 0.15 & 9.5 & 90 & 45.43 & 30.55 & 10.36 & 66.6 & 0.63 & 0.67 & 0.34 \\
\hline 5.25 & 19 & 2.36 & 0.6 & 0.15 & 9.5 & 90 & 51.04 & 28.11 & 9.88 & 67.67 & 0.51 & 0.55 & 0.35 \\
\hline 5.1 & 19 & 2.36 & 0.6 & 0.15 & 9.5 & 90 & 47.07 & 28.26 & 10.86 & 65.24 & 0.52 & 0.6 & 0.38 \\
\hline 5.2 & 19 & 2.36 & 0.6 & 0.15 & 9.5 & 90 & 51.76 & 24.35 & 11.19 & 67.69 & 0.49 & 0.47 & 0.46 \\
\hline 5.13 & 19 & 2.36 & 0.6 & 0.15 & 9.5 & 90 & 46.41 & 29.62 & 9.65 & 65.51 & 0.55 & 0.64 & 0.33 \\
\hline 5.21 & 19 & 2.36 & 0.6 & 0.15 & 9.5 & 90 & 46.52 & 29.66 & 10.28 & 62.86 & 0.44 & 0.64 & 0.35 \\
\hline 5.25 & 19 & 2.36 & 0.6 & 0.15 & 9.5 & 90 & 49.36 & 28.05 & 8.78 & 62.84 & 0.36 & 0.57 & 0.31 \\
\hline 5.2 & 19 & 2.36 & 0.6 & 0.15 & 9.5 & 90 & 47.28 & 23.17 & 10.37 & 66.19 & 0.56 & 0.49 & 0.45 \\
\hline 5.25 & 19 & 2.36 & 0.6 & 0.15 & 9.5 & 90 & 49.19 & 29.11 & 12.03 & 61.07 & 0.31 & 0.59 & 0.41 \\
\hline 5.73 & 19 & 2.36 & 0.6 & 0.15 & 9.5 & 90 & 47.78 & 22.51 & 9.97 & 64.96 & 0.49 & 0.47 & 0.44 \\
\hline 5.35 & 19 & 2.36 & 0.6 & 0.15 & 9.5 & 90 & 47.61 & 29.36 & 12.04 & 62.54 & 0.4 & 0.62 & 0.41 \\
\hline 5.25 & 19 & 2.36 & 0.6 & 0.15 & 9.5 & 90 & 48.25 & 28.92 & 12.39 & 65.39 & 0.5 & 0.6 & 0.43 \\
\hline 5.48 & 19 & 2.36 & 0.6 & 0.15 & 9.5 & 90 & 45.12 & 29.31 & 10.81 & 62.52 & 0.46 & 0.65 & 0.37 \\
\hline 5.27 & 19 & 2.36 & 0.6 & 0.15 & 9.5 & 90 & 45.05 & 23.15 & 11.73 & 62.22 & 0.45 & 0.51 & 0.51 \\
\hline 5.22 & 19 & 2.36 & 0.6 & 0.15 & 9.5 & 90 & 50.79 & 26.51 & 7.47 & 65.83 & 0.44 & 0.52 & 0.28 \\
\hline
\end{tabular}




\subsection{Control sieves:}

In the Bailey method, there are three main control sieves to classify the different particles in the aggregate gradation as shown in Figure 5. Starting with the Primary Control Sieve (PCS) which can be defined as the sieve that separates the coarse and fine particles and it is calculated based on the Nominal Maximum Aggregate Size (NMAS) [[28]] as follows:

$$
P C S=0.22 * N M A S
$$

The value of 0.22 was adopted from the packing theory as an average of aggregate diameter ratios that theoretically ranges from 0.15 for rounded aggregate to 0.29 for flat aggregates. The second control sieve is called the secondary control sieve (SCS) and the main objective of this control point is to split the fine part into two further fractions and the SCS is calculated based on the PCS as follows:

$$
S C S=0.22 * P C S
$$

Finally, the third control point is the Tertiary Control Sieve (TCS) which is calculated as follows:

$$
T C S=0.22 * S C S
$$

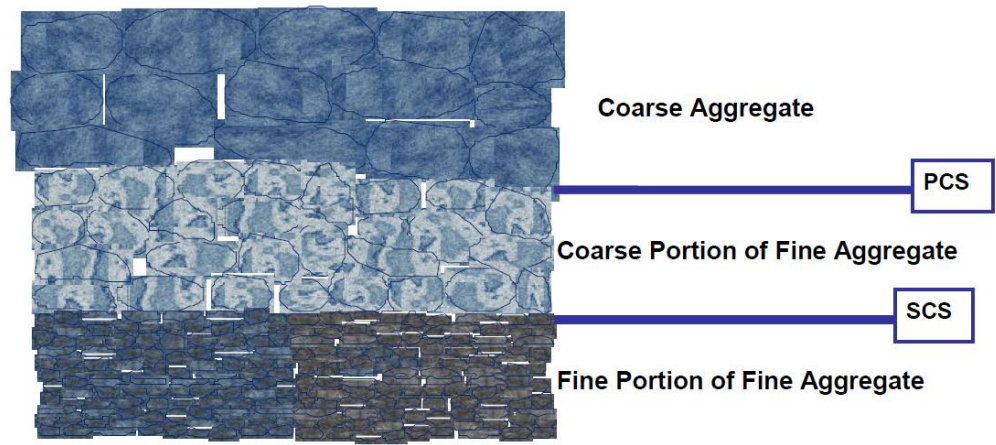

Figure 5. overview of the three control points $[\underline{8}]$

\subsection{Analysis of the Design Blend}

In addition to the previous control points, the Bailey method suggested three additional ratios for the purpose of evaluating the aggregate blend. These ratios are used to understand the aggregate gradation based on the 
previous control points. These ratios are the Coarse Aggregate Ratio (CA Ratio), Fine Aggregate Coarse Ratio (FAc), and Fine Aggregate Fine Ratio (FAf).

\subsubsection{CA ratio:}

The CA ratio is a representation of the interlocking between the coarse particles and provides a better understanding of the void structure between these particles. This ratio introduces a new sieve size which is the half-size (HS) which is half the NMAS:

$$
H S=\frac{N M A S}{2}
$$

The aggregate particles between the two sizes HS and PCS are called the interceptors and changing the percentage of aggregate between these two sizes significantly affects the voids in the mineral aggregate (VMA) as the fine part of the coarse aggregate will fill the voids between the coarse part. Interceptors are too large to fit in the voids created by the larger coarse aggregate particles. With a balanced aggregate structure, the mixture should be easy to compact in the field and should adequately perform under load. The CA ratio is calculated as follows:

$$
C A=\frac{\% p a s s i n g(H S)-\% p a s s i n g(P C S)}{100 \%-\% p a s s i n g(H S)}
$$

In general, the $\mathrm{CA}$ ratio plays an important role in understanding the mixture degree of compaction or in other words provides an indication for the compaction. Asphalt mixes with low CA values (lower than 1) have a better degree of compaction than mixes with a large CA ratio. CA ratio of 1 means that the mix contains an equal amount of interceptors and coarser aggregate, which indicates good interlocking between the particles and high degree of compaction. On the other hand, mixes with high CA ratios (more than one) indicate that the mixes contain a large number of interceptors may lead to segregation and produces mixes that are hard to compact. 


\subsubsection{FAc ratio:}

Similar to the previous case, voids will be introduced between the particles of the coarse part of the fine aggregate. Thus, the main objective of the finer particles is to fill the void between these particles. The FAc is used to show the ratio of these fractions and it is estimated using the following equation:

$$
F A c=\frac{\% p a s s i n g(S C S)}{\% p a s s i n g(P C S)}
$$

The desired FAc value should be around 0.5 , as high values of FAc (higher than 0.5) indicate that the mix contains a large amount of fine particles. On the other hand, the very low values of FAc (lower than 0.5) indicate that the mix is not uniformly graded because of the low fine aggregates in the mix.

\subsubsection{FAf ratio:}

The FAc is the most important ratio for understanding the mix air voids and the required binder content because it focuses on the fine particles in the mix, including the filler, and it is calculated using the following equation:

$$
F A f=\frac{\text { \%passing }(T C S)}{\text { \%passing }(S C S)}
$$

\subsubsection{Effect of the FAc and FAf ratio:}

High values of FAc and FAf indicate that the mix contains excessive amount of fine particles. If the ratio of any of these two ratios goes higher than 0.5 , it indicates that the mix will show a "hump" in the sand portion of the gradation curve of a 0.45 gradation chart, which is generally accepted as an indication of a potentially tender mixture. On the other hand, if the ratios are lower than the guidelines, the gradation is not uniform. These mixtures are generally gap-graded and have a "belly" in the 0.45 -power grading chart, which can indicate instability and may lead to compaction problems.

\subsubsection{Summary of the ratios:}

- CA ratio: this ratio describes how the coarse particles of the aggregate are packed together and how these particles compact the 
fine aggregate portion of the aggregate blend that fills the voids created by the coarse aggregate.

- FAc ratio: this ratio shows how the coarse particles of the fine particles are packed together and how these particles compact the material that fills the voids created.

- FAf ratio: this ratio shows how the fine portion of the fine particles are packed together.

Figure 6 summarizes these rations with the three control points. Based on the previous studies and the performance of a large number of asphalt mixes, the Bailey method provides some guidelines for the selection of aggregate gradation. The guidelines are discussed in the study by Aurilio et al [[27]] and are summarized in table 3.
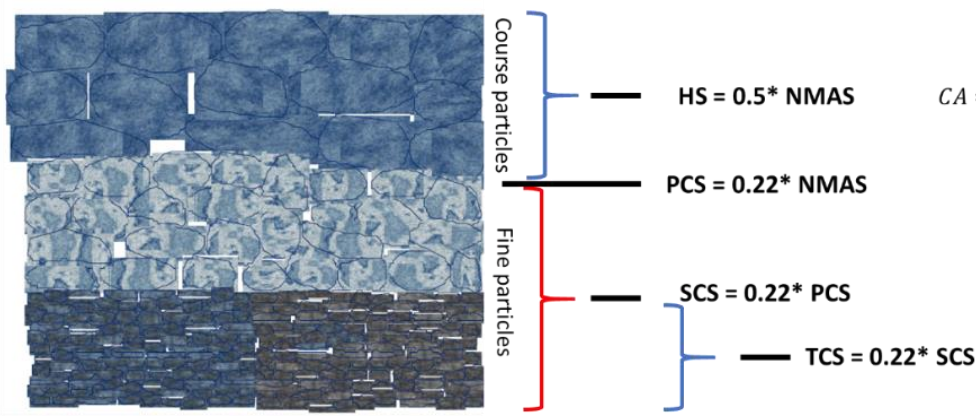

$C A=\frac{\% \text { passing }(H S)-\% \text { passing }(P C S)}{100 \%-\% \text { passing }(H S)}$

$F A c=\frac{\% p a s s i n g(S C S)}{\% \text { passing }(P C S)}$

Figure 6. summarization of the control points and the Bailey ratios (adopted from

$[\underline{8}])$

Table 3. Bailey method ratio guidelines [[27]]

\begin{tabular}{|c|c|c|c|c|c|c|}
\hline $\begin{array}{c}\text { NMAS } \\
(\mathrm{mm})\end{array}$ & 37.5 & 25 & 19 & 12.5 & 9.5 & 4.75 \\
\hline CA ratio & $0.8-0.95$ & $0.7-0.85$ & $0.6-0.75$ & $0.5-0.65$ & $0.4-0.55$ & $0.3-0.45$ \\
\hline FAc ratio & \multicolumn{7}{|c|}{$0.35-0.5$} \\
\hline FAf ratio & \multicolumn{7}{|c|}{$0.35-0.5$} \\
\hline
\end{tabular}

\section{Analysis and results}

\subsection{Analysis of the 3D samples:}

This section focuses on analyzing the 64 asphalt mix samples designed following the $3 \mathrm{D}$ aggregate gradation using the three ratios introduced by the Bailey method. Figures 7 and 8 show the frequency of the CA 
ratios and the FAc ratios. From Figure 7, it can be seen that a small proportion of samples fall on the recommended guidelines as follows:

- $\quad 80 \%$ of the samples have CA ratio less than the specification, which indicates that these samples represent gab graded samples and are prone to segregation.

- $\quad 14 \%$ of the samples are within the Bailey method guidelines.

- $\quad 6 \%$ of the samples have CA ratio higher than the guidelines, which indicates that these samples are hard to compact in the field.

From figure 8, it can be seen that a small proportion of samples fall on the recommended guidelines as follows:

- $\quad 0 \%$ of the samples have FAc ratio less than the recommendations provided by the Bailey method guidelines.

- $\quad 25 \%$ of the samples are within the Bailey method guidelines.

- $\quad 75 \%$ of the samples have FAc ratio higher than the guidelines, which indicates that these samples represent tender mixtures.

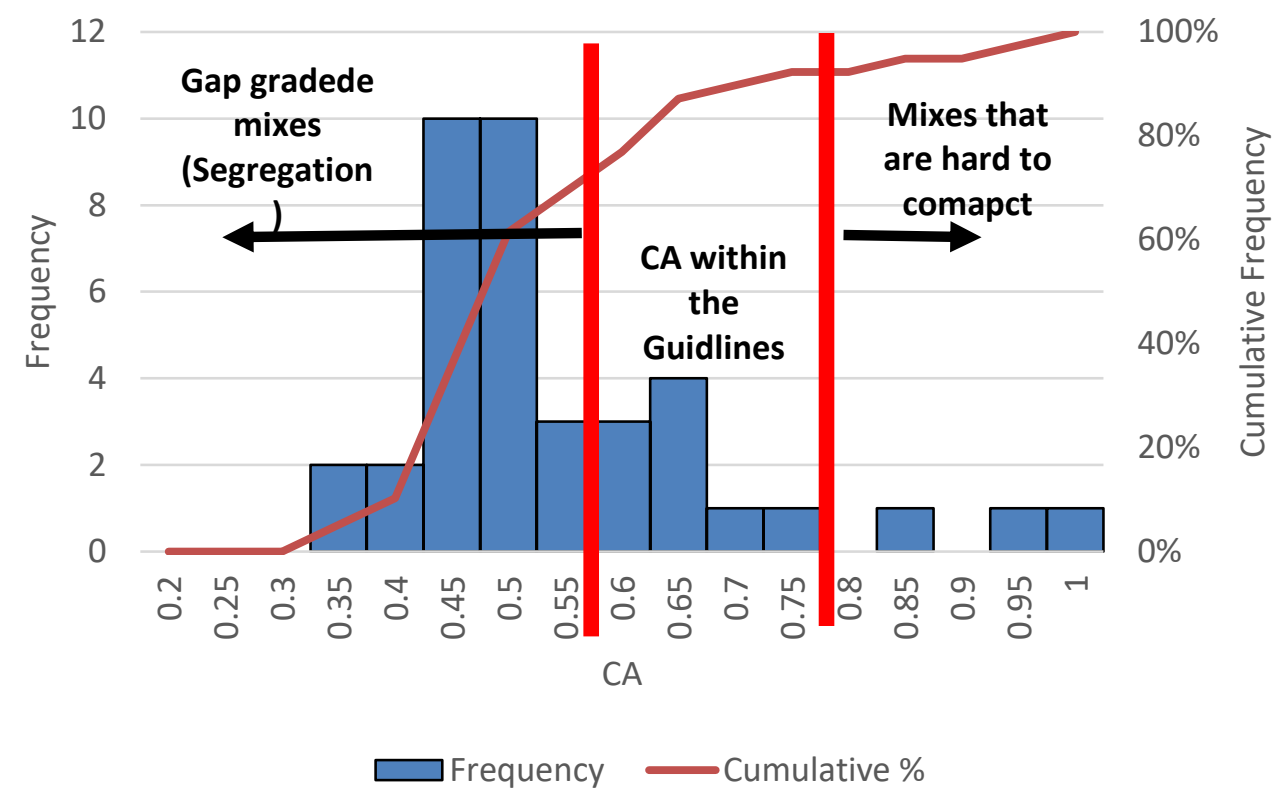

Figure 7. Frequency of the CA ratios for the 3D asphalt mixes 


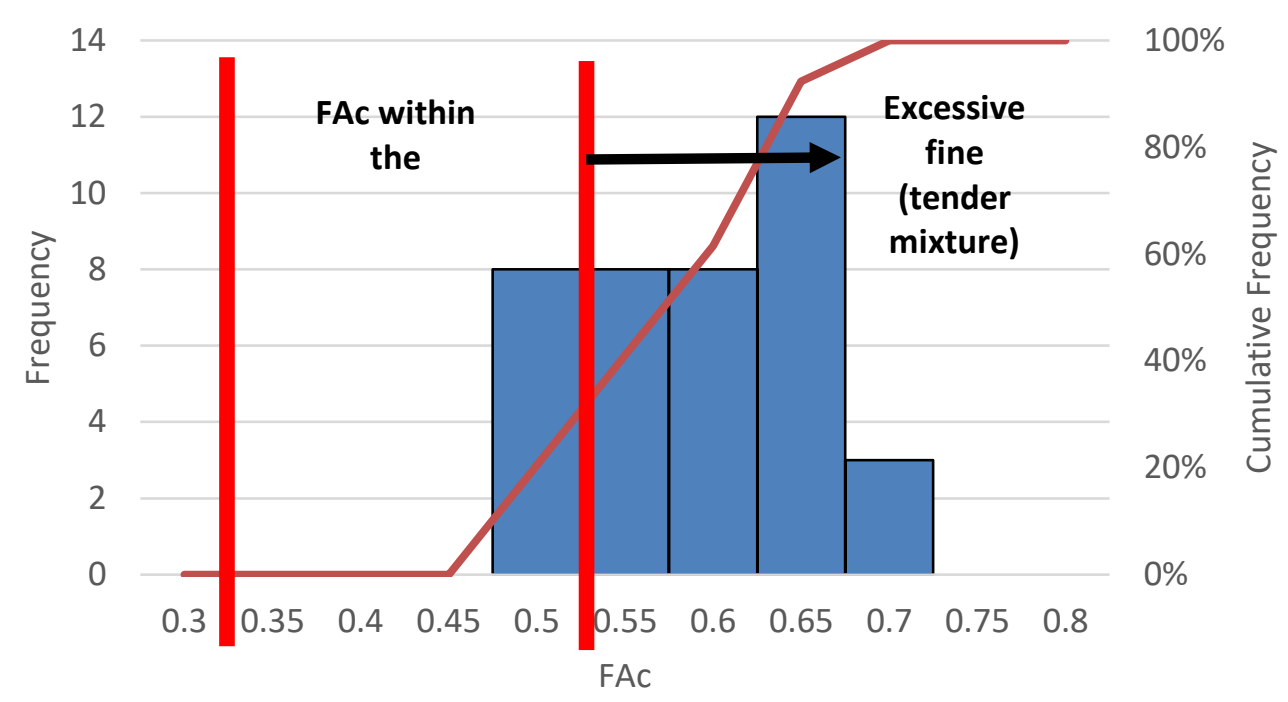

$\square$ Frequency $\longrightarrow$ Cumulative \%

Figure 8. Frequency of the FAc ratios for the 3D asphalt mixes

Additionally, it is important to understand the impact of the NMAS on the Bailey ratios. Thus, a detailed analysis was carried out based on the NMAS. Out of the 64 (3D) samples, there are 12 samples with a NMAS of $25 \mathrm{~mm}$ and 52 samples with a NMAS of $19 \mathrm{~mm}$. Figures 9 and 10 show the frequency of the CA ratios and the FAc ratios for the (3D) samples that have a NMAS of 25 and Figures 11 and 12 show the frequency of the CA ratios and the FAc ratios for the (3D) samples that have a NMAS of $19 \mathrm{~mm}$. Table 4 summarizes the percentage of samples that follow the Bailey method guidelines for the 3D aggregate gradations with 19 and $25 \mathrm{~mm}$ NMAS. Results show that there is a significant difference in the percentage of samples that follow the guidelines. For the CA ratio, $42 \%$ of the samples with $25 \mathrm{~mm}$ NMAS follow the Bailey method guidelines; however, only $10 \%$ of the samples with $19 \mathrm{~mm}$ NMAS follow the Bailey method guidelines. On the other hand, for the FAc ratio, only $10 \%$ of the samples with $25 \mathrm{~mm}$ NMAS follow the Bailey method guidelines; however, $30 \%$ of the samples with $19 \mathrm{~mm}$ NMAS follow the Bailey method guidelines. 


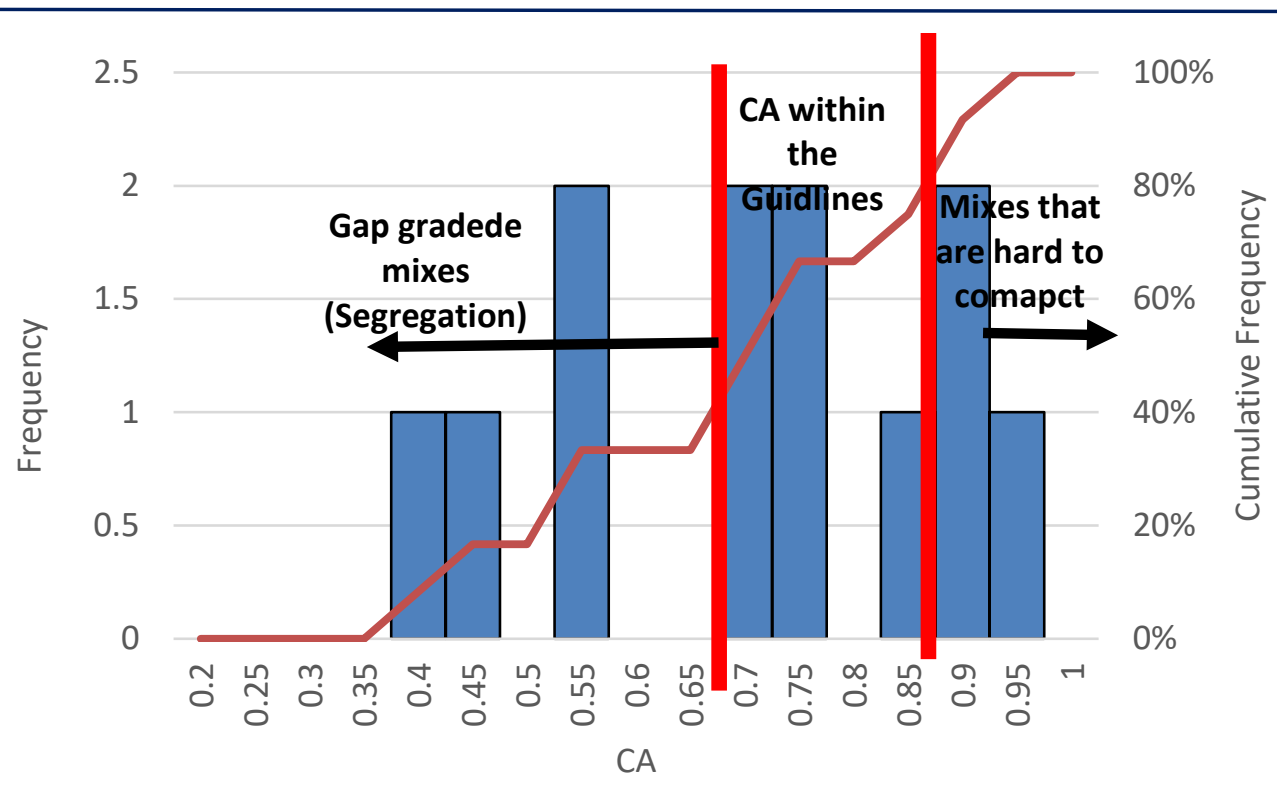

$\square$ Frequency $\longrightarrow$ Cumulative \%

Figure 9. Frequency of the CA ratios for the 3D asphalt mixes with a NAMS of 25 $\mathrm{mm}$

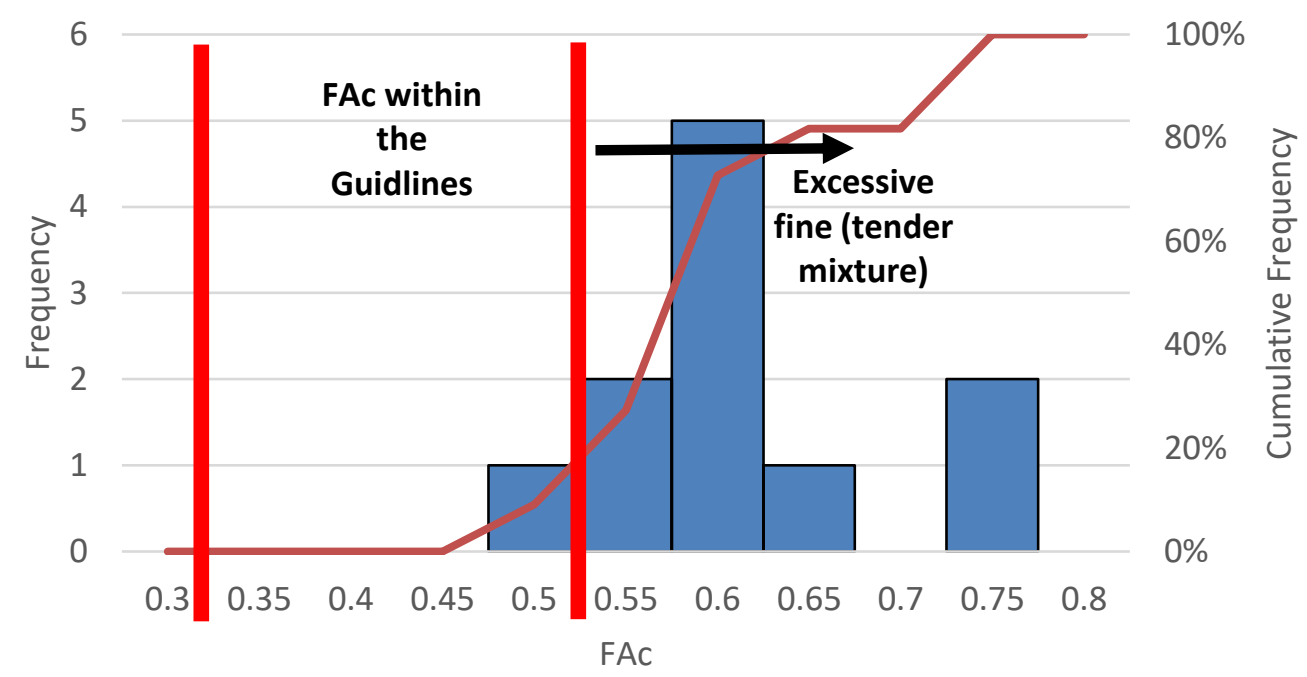

$\square$ Frequency $\longrightarrow$ Cumulative $\%$

Figure 10. Frequency of the FAc ratios for the 3D asphalt mixes with a NAMS of $25 \mathrm{~mm}$ 


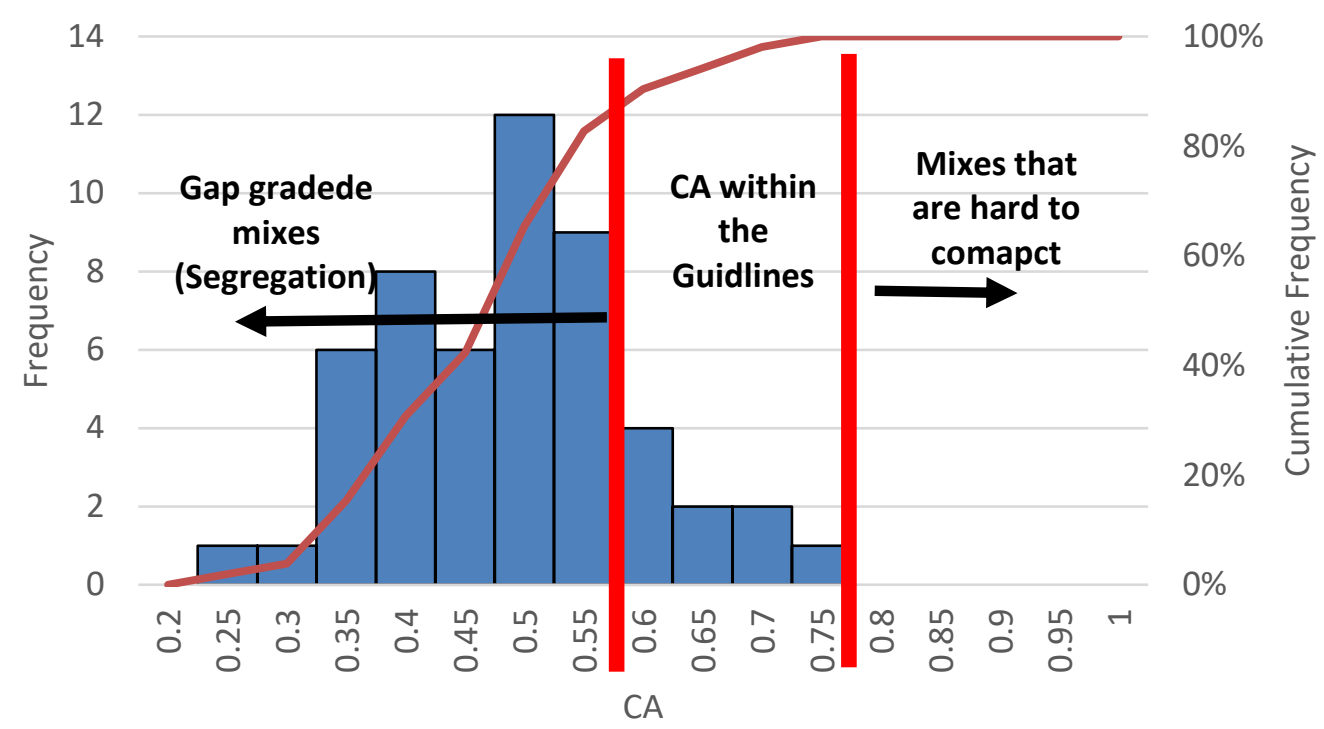

$\square$ Frequency $\longrightarrow$ Cumulative \%

Figure 11. Frequency of the CA ratios for the 3D asphalt mixes with a NAMS of 19 $\mathrm{mm}$

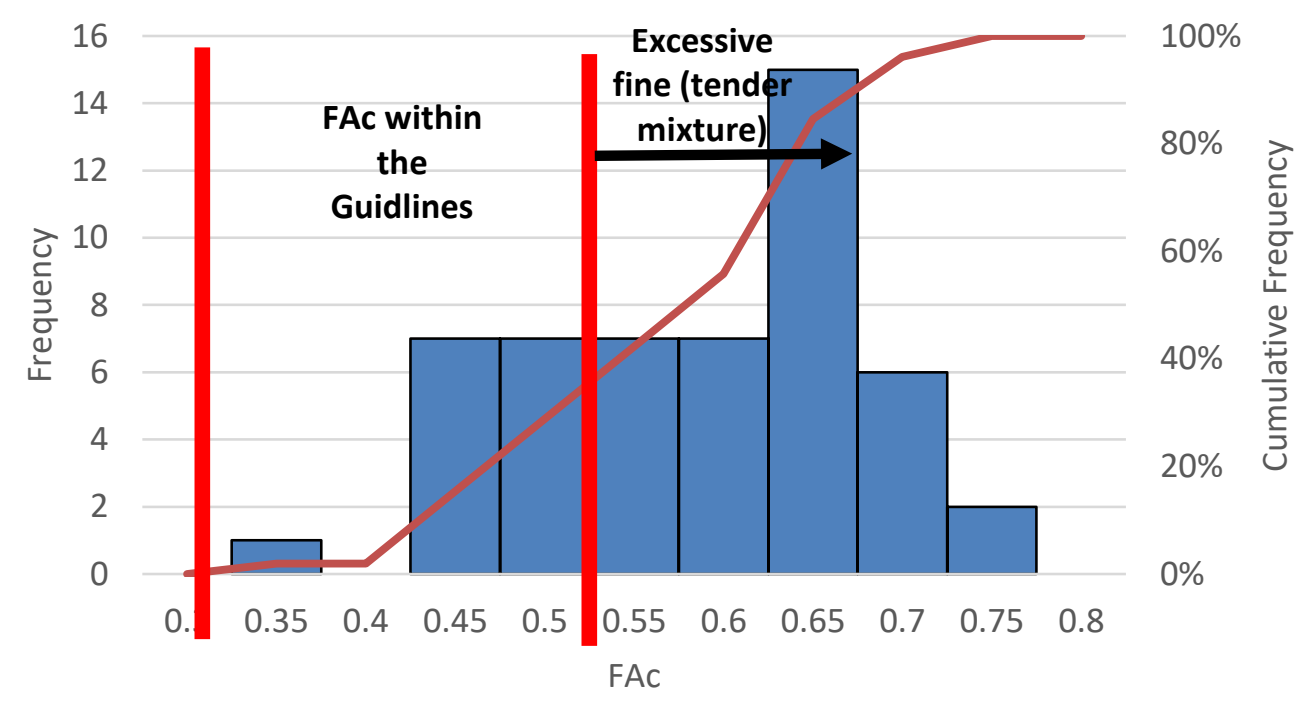

$\square$ Frequency —Cumulative \%

Figure 12. Frequency of the FAc ratios for the 3D asphalt mixes with a NAMS of $19 \mathrm{~mm}$ 
Othman K., Evaluation of the Hot Asphalt Mix Aggregate Gradation Using Bailey Method

Table 4. percentage of samples less than, within, or higher than the Bailey method guidelines for the 3D aggregate gradations for samples with 25 and 19 mm NAMS

\begin{tabular}{|c|c|c|c|c|c|c|}
\hline \multirow[b]{2}{*}{ NMAS } & \multicolumn{3}{|c|}{$\mathrm{CA}$} & \multicolumn{3}{|c|}{ FAc } \\
\hline & $\begin{array}{l}\text { less than } \\
\text { the } \\
\text { guidelines }\end{array}$ & $\begin{array}{l}\text { Within the } \\
\text { guidelines }\end{array}$ & $\begin{array}{l}\text { Higher } \\
\text { than the } \\
\text { guidelines }\end{array}$ & $\begin{array}{l}\text { less than } \\
\text { the } \\
\text { guideline } \\
\mathrm{s}\end{array}$ & $\begin{array}{c}\text { Within } \\
\text { the } \\
\text { guidelines }\end{array}$ & $\begin{array}{l}\text { Higher } \\
\text { than the } \\
\text { guidelines }\end{array}$ \\
\hline $25 \mathrm{~mm}$ & $33 \%$ & $42 \%$ & $25 \%$ & $0 \%$ & $10 \%$ & $90 \%$ \\
\hline $19 \mathrm{~mm}$ & $90 \%$ & $10 \%$ & $0 \%$ & $0 \%$ & $30 \%$ & $70 \%$ \\
\hline
\end{tabular}

\subsection{Analysis of the 4C samples:}

This section focuses on analyzing the 39 asphalt mix samples designed following the $4 \mathrm{C}$ aggregate gradation using the three ratios introduced by the Bailey method. Figures 13 and 14 show the frequency of the CA ratios and the FAc ratios. The percentage of the samples less than, within, and higher than the specifications for the 4C samples are similar to the 3D samples. From Figure 13, it can be seen that a small proportion of samples fall on the recommended guidelines as follows:

- $\quad 77 \%$ of the samples have CA ratio less than the specification, which indicates that these samples represent gab graded samples and are prone to segregation.

- $\quad 16 \%$ of the samples are within the Bailey method guidelines.

- $\quad 7 \%$ of the samples have CA ratio higher than the guidelines, which indicates that these samples are hard to compact in the field.

From figure 14, it can be seen that a small proportion of samples fall on the recommended guidelines as follows:

- $\quad 0 \%$ of the samples have FAc ratio less than the recommendations provided by the Bailey method guidelines.

- $\quad 21 \%$ of the samples are within the Bailey method guidelines.

- $\quad 79 \%$ of the samples have FAc ratio higher than the guidelines, which indicates that these samples represent tender mixtures. 


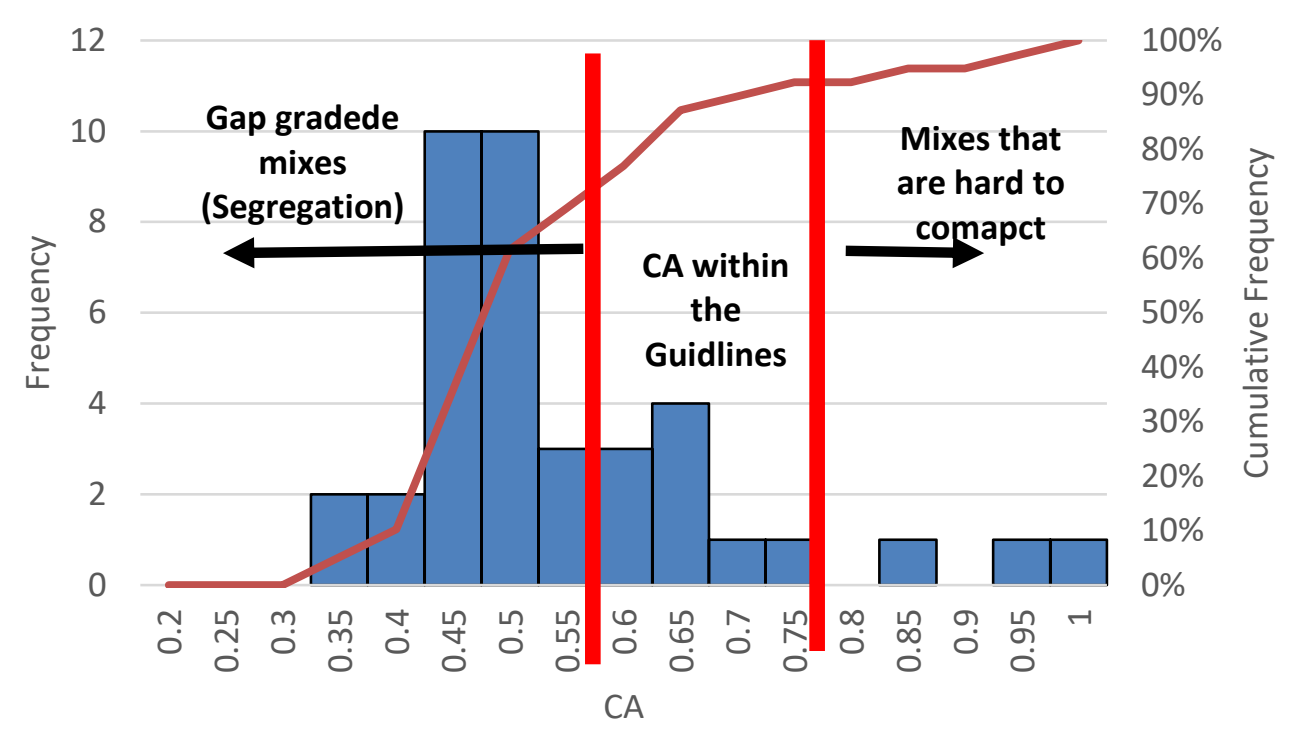

$\square$ Frequency $\longrightarrow$ Cumulative \%

Figure 13. Frequency of the $\mathrm{CA}$ ratios for the $4 \mathrm{C}$ asphalt mixes

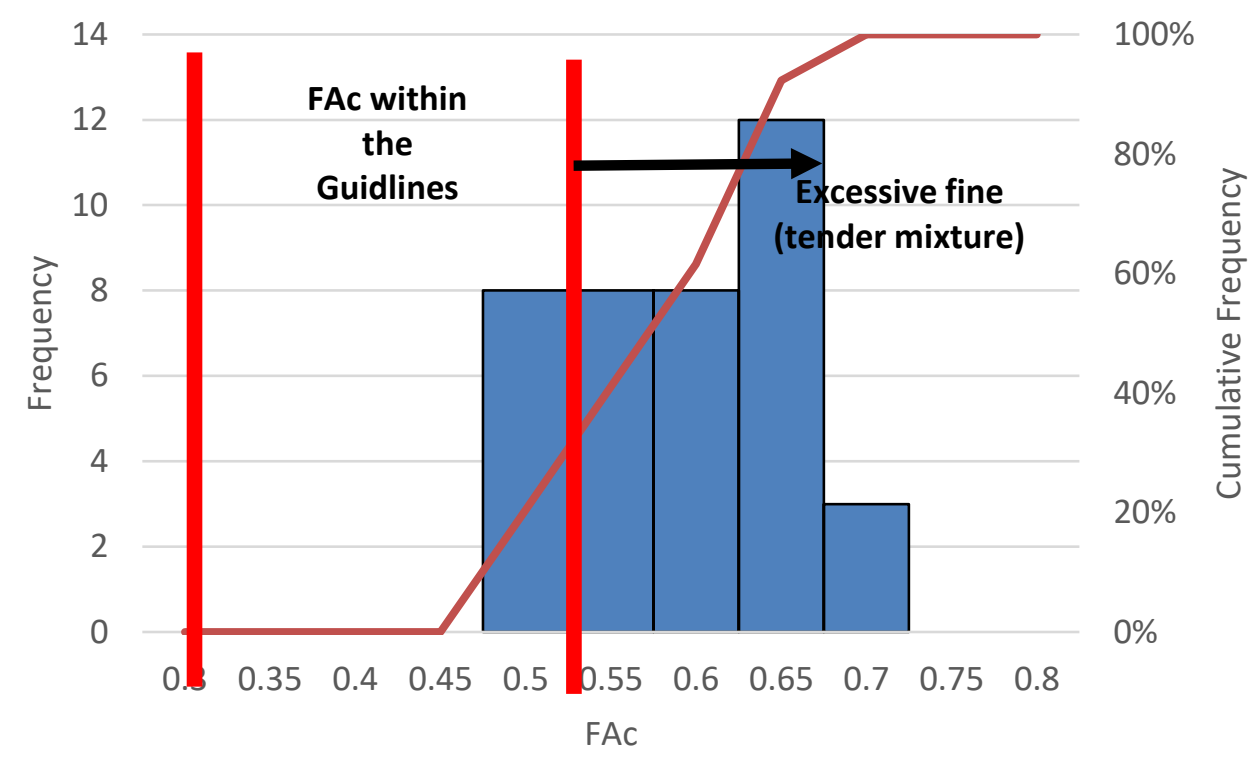

$\square$ Frequency —Cumulative \%

Figure 14. Frequency of the FAc ratios for the 4C asphalt mixes

For the impact of the NMAS on the Bailey ratios, this analysis was not carried out because there are only 2 samples that have a NMAS of 25 
$\mathrm{mm}$ and the remaining 37 samples have a NMAS of $19 \mathrm{~mm}$. thus, the data are not sufficient for analyzing the impact of the NMAS on the Bailey ratios.

\section{Conclusions}

The transportation system is an essential element for any long-term progress of a country that one of the most important indices for the socioeconomic development of nations is the growth of the road network. In 2014, Egypt started a major plan for the development of the transportation infrastructure. This plan managed to significantly improve the quality of roads in Egypt. Thus, the appropriate planning, designing, and construction of road networks with the proper materials and soil properties is an essential step for the construction of these roads. In this study, 103 asphalt mix samples are designed following the trial-and-error approach to select the aggregate gradation that satisfies some aggregate gradation specifications or limits. In this study, the Bailey ratios are used to evaluate the traditional aggregate gradation selection technique and results show that:

- For both the 3D and 4C gradations, Table 5 summarizes the percentage of samples that follow the Bailey method guidelines for the two aggregate gradations used in this study. Results show that almost $80 \%$ of the asphalt mixes designed using the traditional technique with no guidelines regarding the aggregate gradation produces gap graded asphalt mixes that are prone to segregation with $\mathrm{CA}$ ratio lower than the guidelines, 6 to $7 \%$ of the asphalt mixes have $\mathrm{CA}$ ratios higher than the guidelines which indicates that these mixes are hard to compact, and $15 \%$ of the mixes satisfy the Bailey method guidelines and indicate good performance in the field.

Table 5. percentage of samples less than, within, or higher than the Bailey method guidelines for the two aggregate gradations tested

\begin{tabular}{|c|c|c|c|c|c|c|}
\hline & \multicolumn{3}{|c|}{ CA } & \multicolumn{3}{c|}{ FAc } \\
\cline { 2 - 7 } & $\begin{array}{c}\text { less than } \\
\text { the } \\
\text { guideline } \\
\mathrm{s}\end{array}$ & $\begin{array}{c}\text { Within } \\
\text { the } \\
\text { guideline } \\
\mathrm{s}\end{array}$ & $\begin{array}{c}\text { Higher } \\
\text { than the } \\
\text { guideline } \\
\mathrm{s}\end{array}$ & $\begin{array}{c}\text { less than } \\
\text { the } \\
\text { guideline } \\
\mathrm{s}\end{array}$ & $\begin{array}{c}\text { Within } \\
\text { the } \\
\text { guideline } \\
\mathrm{s}\end{array}$ & $\begin{array}{c}\text { Higher } \\
\text { than the } \\
\text { guideline } \\
\mathrm{s}\end{array}$ \\
\hline 3D & $80 \%$ & $14 \%$ & $6 \%$ & $0 \%$ & $25 \%$ & $75 \%$ \\
\hline 4C & $77 \%$ & $16 \%$ & $7 \%$ & $0 \%$ & $21 \%$ & $79 \%$ \\
\hline
\end{tabular}


- $\quad$ For the FAc ratio of both 3D and 4C gradations, results show that almost $80 \%$ of the asphalt mixes designed using the traditional technique produces have excessive fines as the FAc ratio is higher than the guidelines, which indicates that these mixes are tender asphalt mixes. On the other hand, $20 \%$ of the samples satisfy the Bailey method guidelines, which indicates good performance in the field.

- $\quad$ Studying the impact of the NMAS on the three Bailey ratios, results show that the NMAS has a significant influence on the Bailey ratios as follows:

- While most of the samples that have a NMAS of $25 \mathrm{~mm}$ satisfy the CA guidelines (42\%), most of these samples (90\%) have high FAc ratios, which indicates that these samples are tender mixes. Thus, most of the samples that satisfy the CA guidelines do not satisfy the FAc ratio guidelines.

- For the 3D samples with a NMAS of $19 \mathrm{~mm}$, results indicate that most of these samples (90\%) have CA ratios that are lower than the guidelines, which indicates that these samples are gap graded and are prone to segregation. On the other hand, more samples satisfy the FAc ratio guidelines than the samples with a NMAS of $25 \mathrm{~mm}$. However, around $70 \%$ of the samples have high FAc ratios, which indicates that these samples are tender mixes. Thus, most of the samples that satisfy the FAc guidelines do not satisfy the $\mathrm{CA}$ ratio guidelines.

- $\quad$ Based on the previous discussion and analysis, it must be mentioned that it is highly recommended to incorporate an analytical gradation design and evaluation method such as the Bailey design method into the Marshal mix design procedure to improve the performance of the asphalt mixes designed in the field and in order to increase the cycle life of the asphalt mixes in Egypt. However, more research should be undertaken to further validate the Bailey method by using wheel tracking test devices to confirm the improvements in the performance of the asphalt mixtures in Egypt. 


\section{References}

[1]. Egypt Independent. Egypt's road quality now 2nd place in Africa: Prime Minister. 2020. https://egyptindependent.com/egypts-road-quality-now-2ndplace-globally-prime-minister/

[2]. The Global Economy.. Roads quality - Country rankings. 2021. https://www.theglobaleconomy.com/rankings/roads_quality/

[3]. Woof, MJ. .Worldhighways. Egypt's massive road building expansion programme. https://www.worldhighways.com/wh10/news/egypts-massiveroad-building-expansion-programme

[4]. Mousa, K.M., Abdelwahab, H.T., Hozayen H.A., Models for estimating optimum asphalt content from aggregate gradation. Proceedings of the Institution of Civil Engineers - Construction Materials, 174(2): 69-74, 2021, https://doi.org/10.1680/jcoma.18.00035

[5]. Othman, K.M.M., and Abdelwahab, H., Prediction of the Optimum Asphalt Content Using Artificial Neural Networks. Metallurgical and Materials Engineering Journal, Association of Metallurgical Engineers of Serbia AMES. 2021. https://doi.org/10.30544/579

[6]. Ma, T., Huang, X., Zhao, Y., Yuan, H., Ma, X. Degradation behavior and mechanism of HMA aggregate, J. Test. Eval. 40 (5) (2012) 697-707.

[7]. Sangsefidi, E. Ziari, H. Sangsefidi, M. The effect of aggregate gradation limits consideration on performance properties and mixture design parameters of hot mix asphalt, KSCE Journal of Civil Engineers 20(1): 385392, 2015.

[8]. Aho, B. et al., Bailey Method for Gradation Selection in Hot-Mix Asphalt Mixture Design. TRANSPORTATION RESEARCH CIRCULAR. ISSN 0097-8515. Number E-C044 October 2002. Transportation Research Board.

[9]. Ahlrich, R.C. Influence of Aggregate Gradation and Particle Shape/Texture on Permanent Deformation of Hot Mix Asphalt Pavements, Army Engineer Waterways Experiment Station Vicksburg MS Geotechnical Lab. 1996.

[10]. Button, J.W., Perdomo, D., and Lytton, R.L. Influence of Aggregate on Rutting in Asphalt Concrete Pavements, Transportation Research Board. 1990.

[11]. Stakston, A.D., and Bahia, H. The Effect of Fine Aggregate Angularity, Asphalt Content and Performance Graded Asphalts on Hot Mix Asphalt Performance, University of Wisconsin - Madison, Department of Civil and Environmental Engineering. 2003.

[12]. Bissada A F,. Resistance to compaction of asphalt paving mixtures and its relationship to stiffness." ASTM STP 829, USA. 1984.

[13]. El-Basyouny, M.M. and Mamlouk, M.S., Effect of aggregate gradation on rutting potential of Superpave mixes, Paper presented at 78th annual meeting of the Transportation Research Board, Washington D.C. 1999.

[14]. Vavrik, W.R., Asphalt mixture design concepts to develop aggregate interlock (Doctoral dissertation), University of Illinois at UrbanaChampaign), 2000.

[15]. Vince A, Pine WJ, Lum P. The Bailey method-achieving volumetric and HMA compatibility. Course Materials and Handouts (2009) 
[16]. Vavrik WR, Huber G, Pine WJ, Carpenter SH, Bailey R. Bailey method for gradation selection in hot-mix asphalt mixture design. Transportation Research Board Circular No.EC044, Natl Res Counc, Washington DC. 2002.

[17]. Vavrik W.R., Pine W.J., Huber G., Carpenter S.H. The Bailey method of gradation evaluation: the influence of aggregate gradation and packing characteristic on voids in the mineral aggregate. J Assoc Asphalt Paving Technol 70. 2001.

[18]. Zaniewski, J.P., Mason, C., An Evaluation of The Bailey Method to Predict Voids in The Mineral Aggregate, Division of Highways, Charleston, WV, 2006.

[19]. Thompson, G., Investigation of the Bailey Method for the design and analysis of dense-graded HMAC using Oregon aggregates. Final report, Oregon Department of Transportation, Research Unit. SPR-304-311, 2006.

[20]. Zhu, W. Li, H.Z., Ma, S.R., Liu, D.B., Application of Bailey Method for Aggregate Grading Design of Continuous Dense Gradation Asphalt Mixture, in: Advanced Materials Research. Trans Tech Publications, 2012, Vol. 413, pp. 154-159. doi:10.4028/www.scientific.net/AMR.413.154

[21]. Shang, G.T., Takahashi, O., Maekawa, R. Recommended combination of the Bailey parameters in Superpave gradation design for Japanese airfield pavements, Int. J. Pavement Res. Technol. 6 (6) (2013) 704-713.

[22]. Manjunath, K.R., Poornachandra N.B., Design of hot mix asphalt using bailey method of gradation, Int. J. Res. Eng. Tech. 03 (06) (2014) 386-393, https://doi.org/10.15623/ijret.2014.0306072

[23]. Teklu, W. Effect of Gradation of aggregates on the rutting performance of hot mix asphalt. (Doctoral dissertation), ADDIS ABABA UNIVERSITY ADDIS ABABA, 2015.

[24]. Oufa, M.S., Abdolsamedb, A.A., Controlling rutting performance of hot mix asphalt, Int. J. Sci. Eng. Res. 6 (12) (2016).

[25]. Komba, J.J., Maina, J.W., Horak, E., Steyn, W.J., Relationship between aggregate packing characteristics and compactability of Hot-Mix Asphalt mixes, in: Airfield and Highway Pavements 2019: Testing and Characterization of Pavement Materials, American Society of Civil Engineers, Reston, VA, 2019, pp. 183-194.

[26]. Jones, W., The Bailey Method, A Tool Jbr Evaluating HMA Volumetrics and Field Compatibility. 2006.

[27]. Aurilio, V. Pine, WJ. Lum, P. Bailey Method - Achieving Volumetrics and HMA Compactability. Fiftieth Annual Conference of the Canadian Technical Asphalt Association (CTAA). Victoria British Columbia, Canada. 2005.

[28]. Vavrik, W.R., Pine, W.J., Carpenter, S.H., Aggregate blending for asphalt mix design: Bailey method, Transp. Res. Rec. 1789 (1) (2002) 146-153. 


\section{تقييم تأثير تدرج الركام على الخلطة الإسفلتية باستخدام طريق بايلي}

الملخص

يعد اختيار تدرج الركام في عمليه تصميم الخلطة الإسفلتية من اهم خطوات التصميم لما

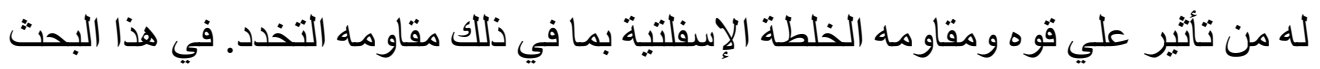
سيتم تقييم الاجراءات الحالية الخاصة باختيار تدرج الركام في الخلطات الإسفلتية

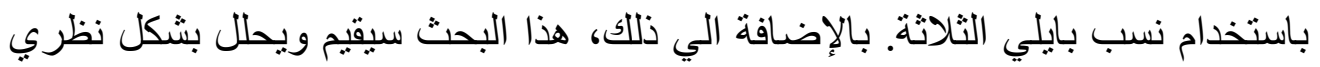

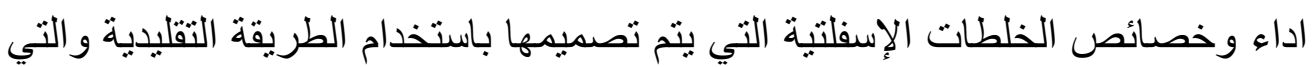

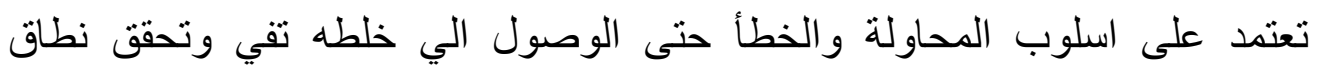
المو اصفات. تبين النتائج ان ع ( ٪ من العينات التي يتم تجهيز ها باستخدام الطريقة التقليدية

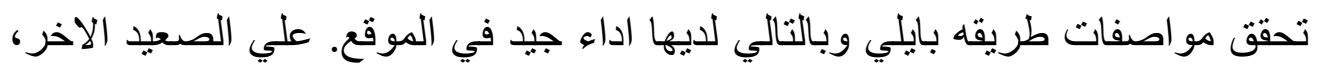

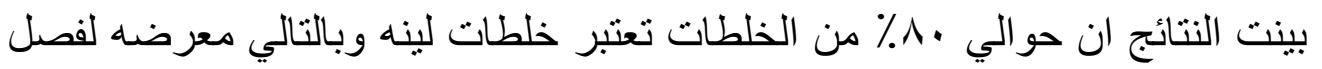

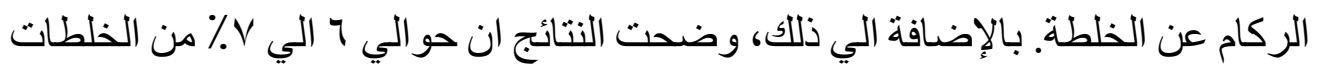
تعاني من صعوبة في دمكها في الموقع. بناء على نتائج هذا البحث فانه يوصي باتي باستخدام

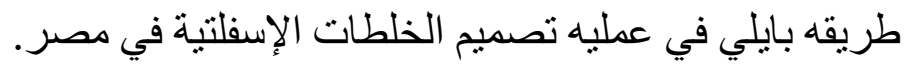

